\title{
Surface subsidence monitoring in mining area of SBAS-InSAR based on Sentinel-1A
}

In this study, the surface subsidence caused by underground mining is monitored by the technique of SBAS-InSAR. The second west mining area of Longshou mine, Jinchang Jinchuan Cu-Ni sulfide mine, Gansu province, is selected as the research area for the experiment. The 29 scene elevation rail Sentinel-1A image data from 2019.03-2020.3 are analyzed for the sequence analysis of the SBAS-InSAR. The vertical subsidence rate and cumulative subsidence results of the surface sequence of the mining area are obtained. According to the study, the minimum error of cumulative sedimentation between SBAS-InSAR and D-InSAR is $0.1 \mathrm{~mm}$, the maximum error is $21.37 \mathrm{~mm}$, and the median error is $\pm 6.65 \mathrm{~mm}$. The minimum error of cumulative settlement between SBAS-InSAR and levelling is $0.66 \mathrm{~mm}$, the maximum is $23.74 \mathrm{~mm}$, and the median error is $\pm 10.79 \mathrm{~mm}$. The results show that the application of the SBAS-InSAR technique in the monitoring of surface subsidence in the mining area is reliable, which provides an important basis for the subsequent safe mining in the mining area.

Keywords: SBAS-InSAR; D-InSAR; surface subsidence; levelling; time series analysis.

\subsection{Introduction}

$\mathrm{N}$ ickel has good mechanical strength, ductility and chemical stability, and has become an indispensable metal in the modern system of various industries (Yan, 2017). China is rich in nickel resources, of which Gansu province has the largest reserves, accounting for $62 \%$ of the total nickel reserves in China. Jinchuan copper nickel sulfide deposit is located in Jinchang city, Gansu province, China. According to the exploration sequence, it can be divided into four mining areas: I, II, III and IV. West 2 mining area of Longshou coal mine is located in the west of mining area I, which is the northwest extension of ore bearing rock mass in mining area I. After mineralization, it is staggered by northeast $\mathrm{F}_{8}$ fault, with a displacement of about $800 \mathrm{~m}$ to the south relative to mining area $\mathrm{I}$, the north part of the mining area is

Messrs. Zhou Wentao, Zhang Wenjun, Geng Shihua, Deng Yuntao, Liu Xianglong, School of Environment and Resource, Southwest University of Science and Technology, Mianyang S\&T City Division National Remote Sensing Center of China, Mianyang 621010, Sichuan, China.
$\mathrm{F}_{1}$ fault (An and Li, 2018). Nickel mining has made great contribution to social development, but it also leads to surface subsidence, surface cracks and ecological damage in the mining area. In 2016, affected by faults activities, the 5-7 stopes at $1610 \mathrm{~m}$ level in West 2 mining area collapsed to the surface. In order to ensure the safety of life and property of residents in the mining area, maximize the recovery of nickel resources and improve the economic efficiency of mine production, it is very important to monitor the surface subsidence of mining area.

The traditional measurement technologies (such as levelling, traverse survey, GPS, etc.) can only provide deformation information of a single point. For large-scale mining area surface subsidence monitoring, the traditional measurement technology is limited by the defects of long time-consuming, heavy workload and bad environment, so it cannot timely reflect the surface subsidence of mining area. Recent years, with the rise of Differential Interferometry Synthetic Aperture Radar (D-InSAR), it has made up for the shortcomings of traditional measurement technologies. It has gradually become a research topic for scholars around the world to monitor the surface deformation through differential interferometry processing of multi scene SAR images in the study area (Zhang, et al., 2014; Guo, et al., 2017; Bai, et.al., 2019; Li, et al., 2018). However, the monitoring accuracy of DInSAR is easily affected by the spatial-temporal incoherence and atmospheric effects. Small baseline subset proposed by Berardino in 2002 can effectively reduce the effects of temporal and spatial incoherence and atmospheric delay ( $\mathrm{Xu}$, et al., 2019; Xiao, et al., 2019). Scholars have achieved some ideal results by using SBAS-InSAR technology to monitor the surface deformation of the mining area. Yin and others applied the SBAS-InSAR technology to the Lengshuijiang tin mine to obtain the subsidence sequence diagram, which effectively revealed the development and evolution process of the mining area settlement (Yin, et al., 2011). Alex et al. monitored the surface subsidence caused by underground mining in a coalfield in Australia (Ng, et al., 2010). Liu, Huaand others combined SBAS-InSAR and D-InSAR to monitor the surface deformation of mining area (Liu, et al., 2014; Hua, et al., 2020). 
In this paper, taking the West 2 mining area of Jinchuan Longshou mine as the research area, using SBAS technology, the data of 29 scenes sentinel-1A in the study area are processed to obtain the time series of vertical surface subsidence in the study area. The results are compared to DInSAR results and levelling results, and the feasibility of SBAS method in the application of surface subsidence in such mines is evaluated.

\subsection{Survey and data at sources of the study area}

\subsection{Overview OF THE STUDY AREA}

The study area is located in the West 2 mining area of Longshou Mine in Jinchang city, Gansu province (Fig.1A), with an area of about $1.1 \mathrm{~km}^{2}$. The mining area is located in a relatively flat terrain with an altitude of $1500-1800 \mathrm{~m}$, belonging to a temperate continental climate. The surface water system is not developed and has been dried up for a long time. The water source is mainly from atmospheric precipitation. The strata in the mining area are mainly composed of banded migmatite, white marble, marble, quartz mica schist, gneiss, graphite bearing schist, migmatized eclogite bearing gneiss, serpentinized marble with homogeneous migmatite, biotite quartz gneiss, etc. (An and Li, 2018). In 2016, the 5-7 stopes at $1610 \mathrm{~m}$ level in West 2 mining area collapsed to the surface (Fig.1B), and the surface cracks are obvious (Fig.1C). The surface of the mining area is drying with a small amount of plants. The surface subsidence area is surrounded by barbed wires. There are only some industrial construction areas nearby and no residential areas.

\subsection{DATA SOURCES}

\subsubsection{SAR data}

In this paper, SAR images from 2019.03.22 to 2020.03.28 are selected. The image parameters are shown in Table 1, the image data of participants in the experiment are shown in Table 2. POD Precise Orbit Ephemerides is introduced into the preprocessing process.

\subsubsection{Measured data}

The study area is located in the central part of Jinchang city, Gansu province. The surface subsidence is caused by underground mining in recent years. According to the underground mining construction scope of the study area, 18 benchmark points are randomly arranged on the surface, as shown in Fig.2. The traditional levelling method is used to monitor the scope of the study area. TOPCON DL-101C electronic level is used for monitoring. Six times of observation are conducted from April 2019 to September 2019, once a month. The results are analyzed by time series settlement, and the settlement curve of each point is shown in Fig.3.

\subsection{Pinciple and data processing of SBAS-InSAR}

\subsection{SBAS-INSAR PRINCIPLE}

With $N+1$ scenes, $t_{0}, t_{1}, \ldots, t_{n}$, one scene image is taken as the super main image to register and resample all images.

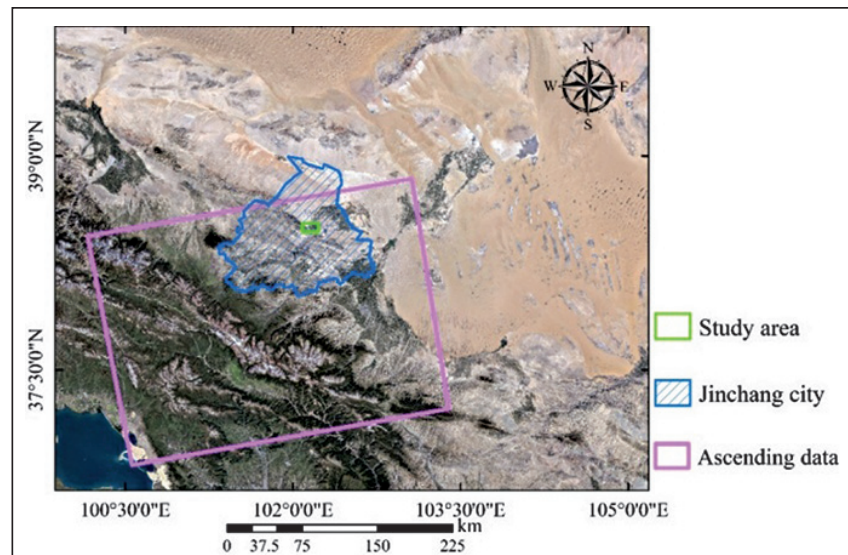

(A) Study area

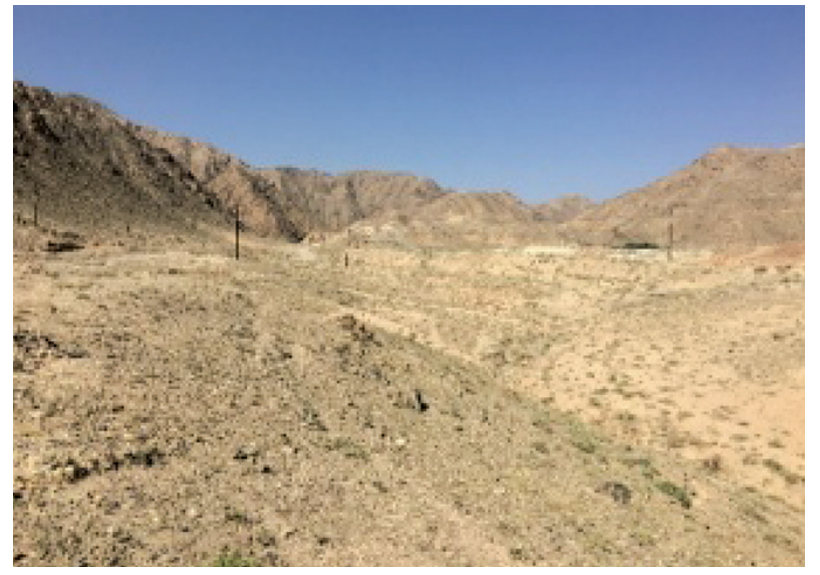

(B) Surface subsidence

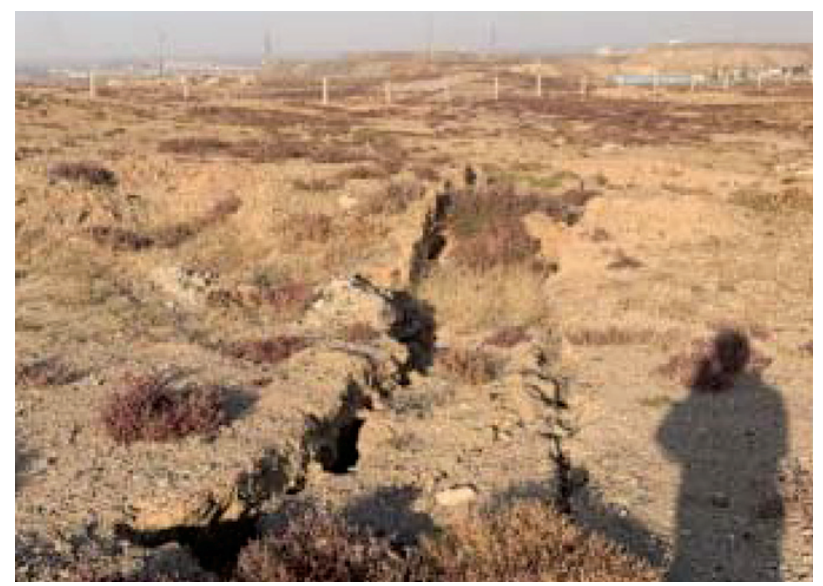

(C) Surface cracks

Fig.1 Study area overview

Then the critical baseline threshold and time baseline threshold are set to obtain $M$ interference pairs meeting the threshold. $M$ satisfies the following conditions:

$$
(N+1) / 2<M<N(N+1) / 2
$$

After removing the terrain effect, the differential interferogram is obtained. Suppose two times $t_{A}>t_{B}$, and $t_{1}$ as 


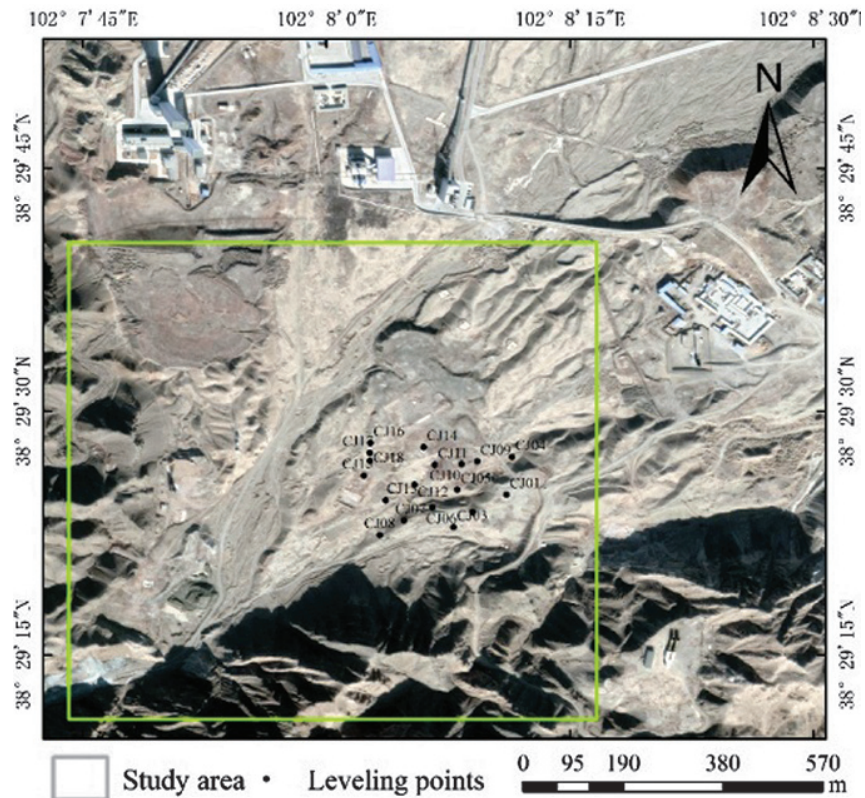

Fig.2 Location of the leveling points

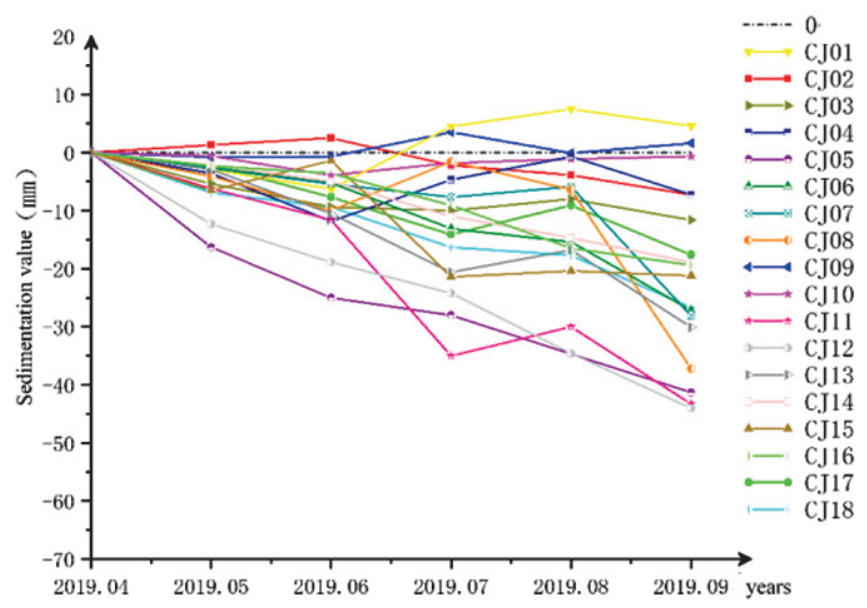

Fig.3 Settlement curve of leveling points sequence

reference time, $j$ inter-ferograms are generated from SAR images obtained between $t_{A}$ and $t_{B}$. After removing terrain phase, the inter-ferometric phase value at $x$ is as follows:

$$
\begin{aligned}
& \delta \varphi_{j}=\varphi_{B}(x, r)-\varphi_{A}(x, r) \approx \frac{4 \pi}{\lambda}\left[d\left(t_{B}, x, r\right)-\right. \\
& \left.d\left(t_{A}, x, r\right)\right]+\Delta \mu_{i}^{\text {topo }}(x, r)+\Delta \mu_{i}^{r e s}(x, r)
\end{aligned}
$$

were $\lambda$ is the central wavelength of the radar, $\varphi$ and $\mu$ are the interference phases, and $d$ is the LOS deformation:

$$
d\left(t_{B}, x, r\right)-d\left(t_{A}, x, r\right)=v_{i}\left(t_{B}-t_{A}\right)
$$

$v_{i}$ is the LOS to average deformation rate from $t_{A}$ to $t_{B}$. Equation (3) can be transformed into:

$$
B v=\delta \varphi
$$

To prevent the rank defect of matrix $B$, the singular value decomposition (SVD) method is used to obtain the unique solution of the SBAS technique (Li, et al., 2019). SBAS technology can effectively reduce the influence of spatialtemporal incoherence, atmospheric delay and other errors, so as to obtain more accurate deformation rate and timing results. The main purpose of the experiment is to study the vertical settlement of the ground surface, and verify its feasibility by combining with the measured leveling data. All settlement results in this paper are vertical deformation results.

\subsection{DATA PROCESSING}

The experiment is based on SAR scape version 5.2.1 for SBAS data processing. 29 Sentinel-1A images are used to set the critical baseline threshold of $2 \%$ and the time baseline threshold of 180.SRTM DEM (Shuttle Radar Topology Mission Digital Elevation Model) data with $30 \mathrm{~m}$ resolution is

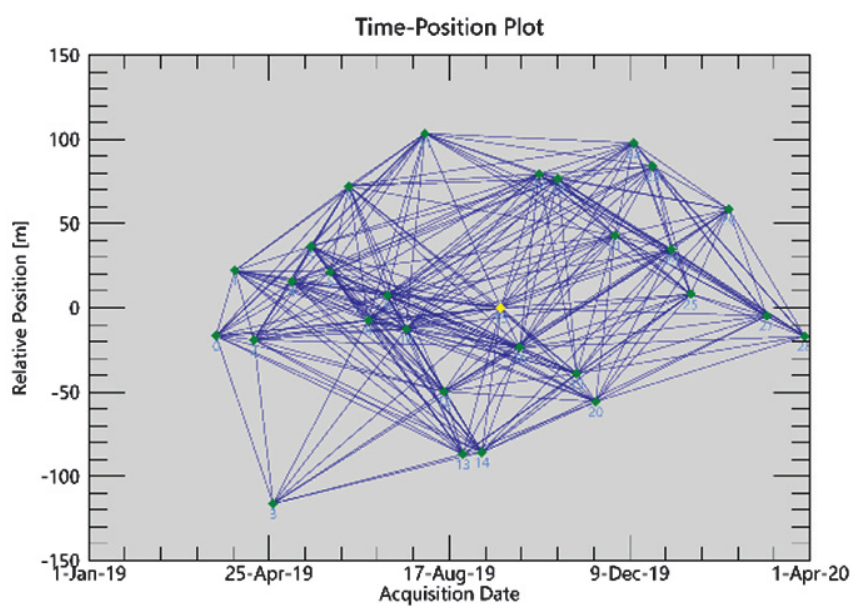

Fig.4 The baseline of time-position

used for image processing. 268 interference pairs are generated for differential interference processing and 3D unwrapping, and the baseline of time-position is shown in Fig.4.

According to the generated interference results and phase unwrapping results, the interference pairs with poor effect are eliminated. The threshold value of unwrapping correlation coefficient is set to 0.2 , then stable control points are selected for orbit refining and relevelling. The influence of atmospheric phase error is removed; the results of LOS to annual average settlement rate and time series cumulative settlement are obtained, and finally converted to vertical results. The specific processing flow is shown in Fig.5, and the vertical annual average settlement rate is shown in Fig. 6 while the accumulated settlement is shown in Fig.7.

TABLE 1: BASIC PARAMETERS OF SAR IMAGE IN THE STUDY AREA

\begin{tabular}{ccccccc}
\hline Satellite & Direction & File type & Angle of incidence & Period & Beam mode & Polarization \\
\hline Sentinel-1A & Ascending & SLC & $39.20^{\circ}$ & $12 \mathrm{~d}$ & IW & WV \\
\hline
\end{tabular}


TABLE 2: EXPERIMENTAL DATA LIST

\begin{tabular}{cccccccc}
\hline Number & Get date & Direction & Absolute orbit & Number & Get date & Direction & Absolute orbit \\
\hline 1 & 20190322 & Ascending & 026450 & 16 & 20190918 & Ascending & 029075 \\
2 & 20190403 & Ascending & 026625 & 17 & 20190930 & Ascending & 029250 \\
3 & 20190415 & Ascending & 026800 & 18 & 20191012 & Ascending & 029425 \\
4 & 20190427 & Ascending & 026975 & 19 & 20191024 & Ascending & 029600 \\
5 & 20190509 & Ascending & 027150 & 20 & 20191105 & Ascending & 029775 \\
6 & 20190521 & Ascending & 027325 & 21 & 20191117 & Ascending & 029950 \\
7 & 20190602 & Ascending & 027500 & 22 & 20191129 & Ascending & 030125 \\
8 & 20190614 & Ascending & 027675 & 23 & 20191211 & Ascending & 030300 \\
9 & 20190626 & Ascending & 027850 & 24 & 20191223 & Ascending & 030475 \\
10 & 20190708 & Ascending & 028025 & 25 & 20200104 & Ascending & 030650 \\
11 & 20190720 & Ascending & 028200 & 26 & 20200116 & Ascending & 030825 \\
12 & 20190801 & Ascending & 028375 & 27 & 20200209 & Ascending & 031175 \\
13 & 20190813 & Ascending & 028550 & 28 & 20200304 & Ascending & 031525 \\
15 & 20190825 & Ascending & 028725 & 29 & 20200328 & Ascending & 031875 \\
\hline
\end{tabular}

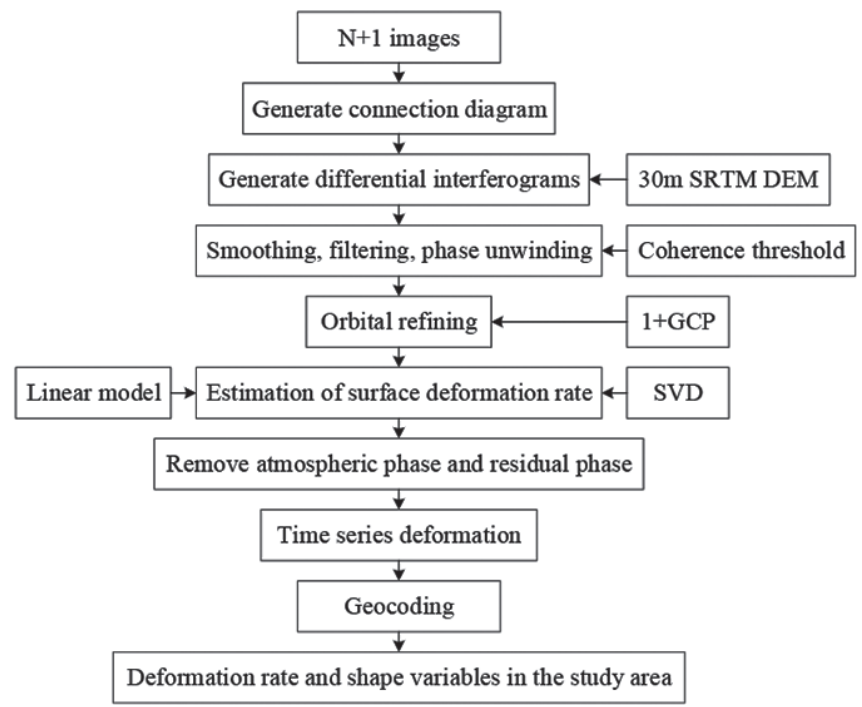

Fig.5 Data processing process of SBAS-InSAR

\subsection{Experimental results and analysis}

\subsection{SBAS-INSAR TIMING ANALYSIS}

As mentioned above, the annual average settlement rate graph in the vertical direction of the study area is obtained by using the SBAS-InSAR technique, as shown in Fig.6. There is a trend of settlement in the study area, and the maximum annual average settlement rate is $101.4 \mathrm{~mm} / \mathrm{a}$. There is no building near the settlement area.

According to the time series analysis of six periods of accumulated settlement from March 2019 to September 2019, as shown in Fig.8, the settlement of the study area changes little from April to May, and the settlement range from June to September is gradually expanded. From July to August, the settlement rate accelerated and the settlement value increased continuously, and the maximum accumulated settlement value is $-40.14 \mathrm{~mm}$.

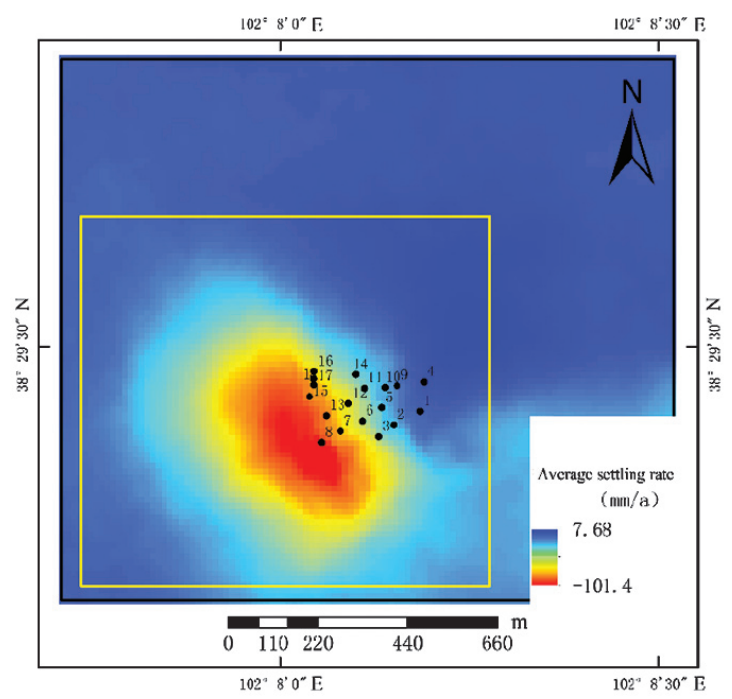

Fig.6 Vertical average annual settlement rate

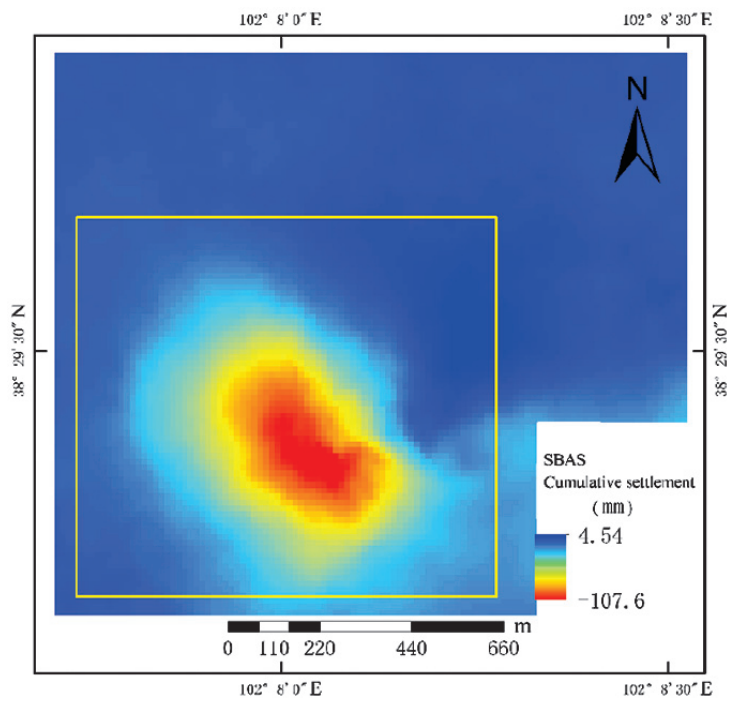

Fig.7 Cumulative settlement 


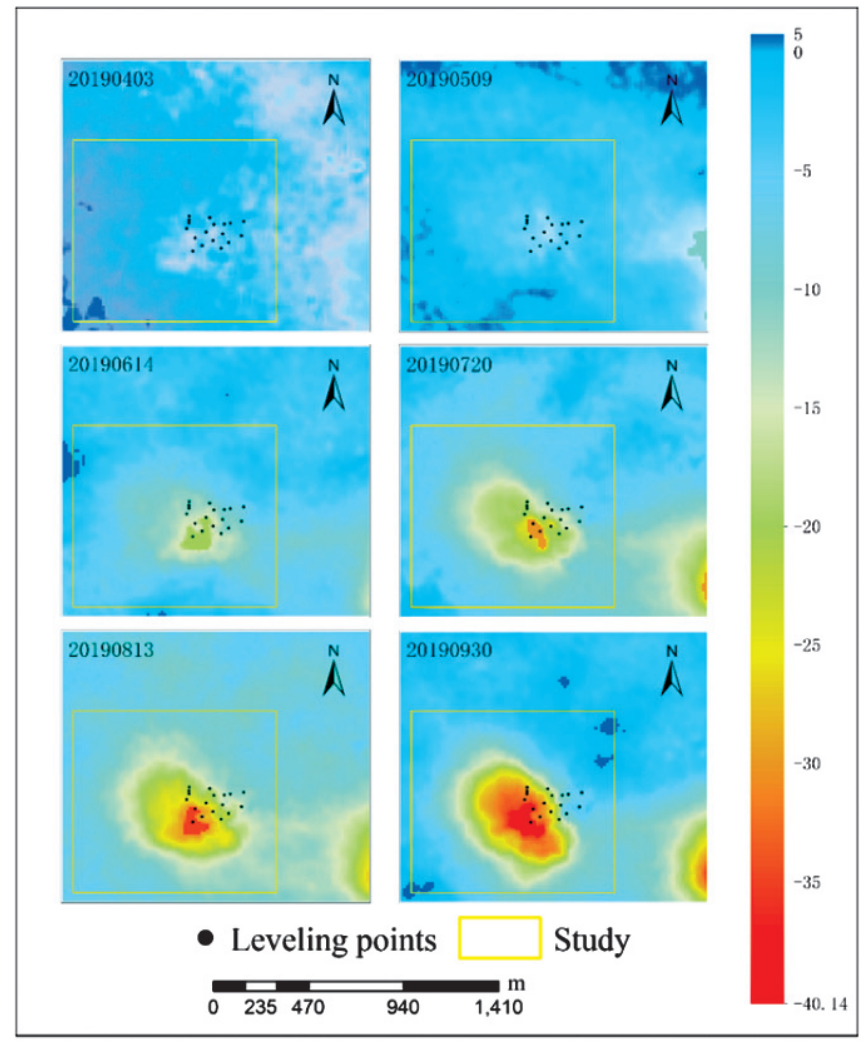

Fig. 8 Temporal sedimentation variation

As shown in Fig.3, the settlement curve of the observation points is relatively stable from April to June, in which CJ01, CJ09 and CJ10 are uplifting, and CJ05 and CJ12 are settling faster; the settlement rate is gradually accelerating from June to September, among which the settlement rates of CJ07, CJ08, CJ11 and CJ15 are the most obvious. Combined with Fig.6, it can be seen that CJ01, CJ04 and CJ09 have less settlement; CJ02, CJ03, CJ05, CJ06, CJ10, CJ11, CJ12 and CJ14 have more settlement; CJ7, CJ8, CJ13, CJ15, CJ16, CJ17 and CJ18 are relatively serious. The settlement point CJ06 and settlement point $\mathrm{CJ} 15$ are extracted to analyze the time series settlement change of SBAS method and levelling method, with the time span from April 2019 to September 2019, as shown in Fig.9. As shown in the figure, the two points are gradually sinking (set April as the starting point, and the settlement change is $0 \mathrm{~mm}$ ). The minimum error of SBAS-InSAR method and levelling method of CJ06 is $2.46 \mathrm{~mm}$, the maximum is $8.26 \mathrm{~mm}$, and the mean square error is $\pm 6.25 \mathrm{~mm}$. The minimum error of SBAS-InSAR method and levelling method of CJ15 is 1.47 $\mathrm{mm}$, the maximum is $11.19 \mathrm{~mm}$, and the mean square error is $\pm 5.54 \mathrm{~mm}$.

\subsection{Cumulative Settlement analysis}

In order to verify the feasibility of SBAS-InSAR results in the mining area, the cumulative settlement from April 2019 to September 2019 is compared and analyzed by using D-InSAR and measured data.

The main image 20190322 and auxiliary image 20190930 are

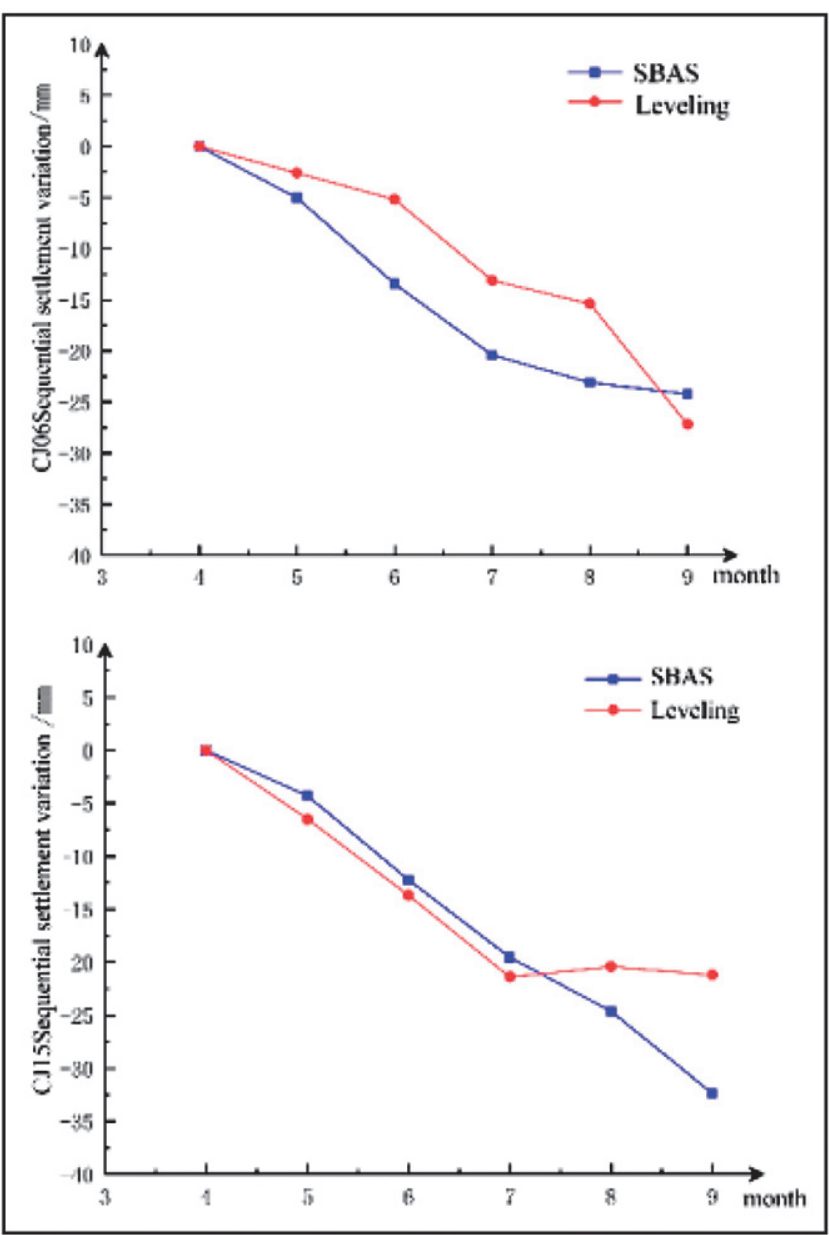

Fig.9 Sequential settlement curve

used for D-InSAR processing. The baseline estimation results show that the spatial baseline is $-19.022 \mathrm{~m}$, which is far less than the critical baseline of $5934.665 \mathrm{~m}$, the temporal baseline is $192 \mathrm{~d}$, and the terrain change represented by a phase change period of DInSAR is $0.028 \mathrm{~m}$. The D-InSAR workflow under SAR scape is used for interference processing, and the accumulated settlement of the study area from 20119.03.22 to 2019.09.30 is finally obtained, as shown in Fig.10, in which the maximum accumulated settlement value can reach -52.66 $\mathrm{mm}$.

See Table 3 and Fig. 11 for the comparison of SBAS-InSAR cumulative settlement with D-InSAR and levelling deformation results. It can be seen that the minimum cumulative settlement error of SBAS-InSAR and D-InSAR is $0.1 \mathrm{~mm}$, and the maximum is $21.37 \mathrm{~mm}$. Only the error of CJ03 and CJ06 is greater than $10 \mathrm{~mm}$, and the mean square error is $\pm 6.65 \mathrm{~mm}$. The minimum cumulative settlement error between SBAS-InSAR and levelling is $0.66 \mathrm{~mm}$, and the maximum is $23.74 \mathrm{~mm}$. The error of CJ05, CJ11, CJ12, CJ15 and CJ17 is more than $10 \mathrm{~mm}$, and the mean square error is $\pm 10.79 \mathrm{~mm}$.

In InSAR processing, the main causes of error are imaging system error and interference model error. The influence of error can be reduced by setting baseline threshold, deleting 
Table 3: Comparison table of cumUlative Settlement Results of SBAS with D-InSAR and LeVelling

\begin{tabular}{|c|c|c|c|c|c|}
\hline Number & SBAS-InSARmm & D-InSARmm & Leveling datamm & $\Delta_{\text {SBAS-DInSAR }} \mathrm{mm}$ & $\Delta_{\text {SBAS-Level }} \mathrm{mm}^{2}$ \\
\hline CJ01 & -5.25 & -2.13 & 4.6 & -3.12 & -9.85 \\
\hline CJ02 & -9.25 & -11.66 & -7.3 & 2.41 & -1.95 \\
\hline CJ03 & -18.47 & -39.84 & -11.6 & 21.37 & -6.87 \\
\hline CJ04 & -5.13 & -7.92 & -7.3 & 2.79 & 2.17 \\
\hline CJ05 & -17.56 & -14.19 & -41.3 & -3.37 & 23.74 \\
\hline CJ06 & -25.27 & -36.39 & -27.2 & 11.12 & 1.93 \\
\hline CJ07 & -31.20 & -37.82 & -28.1 & 6.62 & -3.1 \\
\hline CJ08 & -37.86 & -39.53 & -37.2 & 1.67 & -0.66 \\
\hline CJ09 & -7.56 & -8.85 & 1.6 & 1.29 & -9.16 \\
\hline CJ10 & -10.03 & -9.93 & -0.7 & -0.1 & -9.33 \\
\hline CJ11 & -19.91 & -25.79 & -43.3 & 5.88 & 23.39 \\
\hline $\mathrm{CJ} 12$ & -28.70 & -34.05 & -44.0 & 5.35 & 15.3 \\
\hline CJ13 & -35.72 & -37.05 & -30.1 & 1.33 & -5.62 \\
\hline $\mathrm{CJ} 14$ & -16.24 & -21.01 & -18.9 & 4.77 & 2.66 \\
\hline CJ15 & -32.96 & -35.33 & -21.2 & 2.37 & -11.76 \\
\hline CJ16 & -26.66 & -31.69 & -19.4 & 5.03 & -7.26 \\
\hline CJ17 & -30.35 & -31.84 & -17.6 & 1.49 & -12.75 \\
\hline CJ18 & -31.41 & -34.92 & -26.7 & 3.51 & -4.71 \\
\hline
\end{tabular}

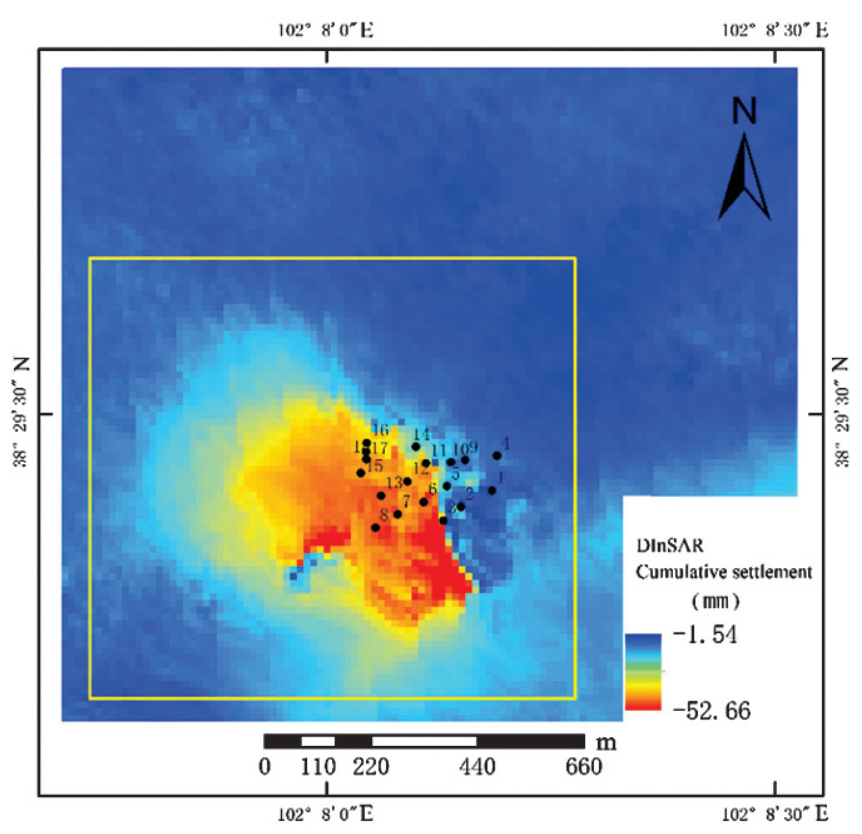

Fig.10 Cumulative settlement of D-InSAR

interference pairs with poor effect, selecting stable GCP points, etc.; levelling error is mainly caused by instrument error, scale error and external factors, so as to reduce the influence of error. In the process of observation, the operation shall be carried out in strict accordance with the instrument use specifications.

Because the levelling data reflects the elevation change of a single point, while SBAS-InSAR and D-InSAR are limited by the resolution of SAR images, they can only reflect the elevation changes of small areas. Therefore, the cumulative settlement curves of SBAS InSAR and D-InSAR are more

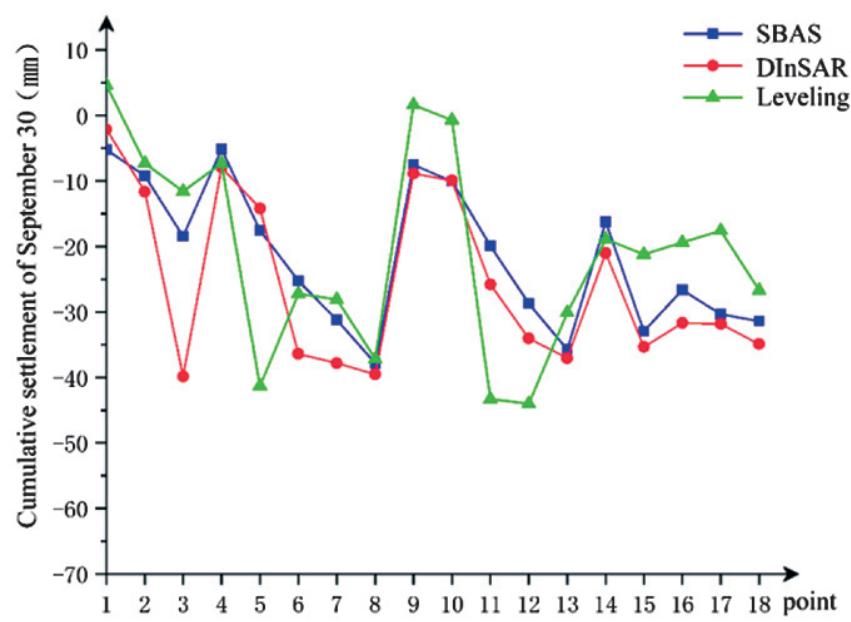

Fig.11 Cumulative settlement at each point

coincident. The SBAS-InSAR cumulative settlement is in good agreement with D-InSAR and levelling results.

\subsection{Conclusion}

In this paper, taking the West 2 mining area of Longshou mine in Jinchuan copper nickel sulfide mine of Jinchang city as the research area, the SBAS-InSAR technology is applied to the surface subsidence monitoring in the mining area. In this experiment, 29 sentinel-1A images are used for SBAS-InSAR processing, and 268 interference pairs are generated by setting critical baseline threshold and time baseline threshold. The coherent coefficient map, filtered inter-ferogram and phase unwrapping map are integrated to extract the high coherence points in the survey area for track refining and relevelling. The time series deformation rate model is 
established and the Singular Value Decomposition (SVD) method is used to calculate the deformation rate. Finally, the vertical annual time series deformation rate and cumulative settlement results are obtained. The results show that the maximum annual average settlement rate is $-101.4 \mathrm{~mm} / \mathrm{a}$ while the maximum cumulative settlement is $-107.6 \mathrm{~mm}$. The subsidence range of the mining area spreads to the northwest and southeast.

In order to verify the feasibility of SBAS InSAR technology in surface subsidence monitoring in the mining area, the cumulative settlement results of 18 observation points from March 22, 2019 to September 30, 2019 are verified by combining D-InSAR and levelling. The results show that the mean square error of the accumulated settlement difference between SBAS InSAR method and D-InSAR method is $\pm 6.65 \mathrm{~mm}$, and that of SBAS InSAR method and levelling method is $\pm 10.79 \mathrm{~mm}$, showing good consistency.

In this paper, SBAS InSAR technology is used to make up for the time-space incoherence of D-InSAR in mining area surface subsidence monitoring. Combined with levelling, the time series analysis of mining area surface subsidence is carried out, which fully proves the feasibility of SBAS InSAR technology in mining area surface subsidence monitoring, and provides an important basis for safe mining in mining area.

\section{References}

[1] Yan Jiaming (2017): Geological characteristics and genesis of Akechukesai copper nickel deposit in Eastern Kunlun, Qinghai [D]. Jilin University, 7-15

[2] An Wenjie, Li Guangkuan (2018): Study on combined overburden technology scheme of caving mining method in West No.2 Mining Area of Longshou Mine [J]. Gold, 2018, 39 (06): 35-38

[3] Zhang Kainan, Yang Zhiqiang, Wu Jifeng(2014): Application of D-InSAR technology in surface subsidence monitoring of Loess Plateau Gully mining area [J]. Surveying and mapping bulletin, (S2): 23-25

[4] Guo Shanchuan, Hou Huping, Zhang Shaoliang, Xu Yaqing, Yang Yongjun (2017): Surface deformation monitoring in Loess Plateau mining area by D-InSAR [J]. Surveying and Mapping Science, 42 (06): 207-212

[5] Bai Zechao, Wang Baocun, JinGuowang, Xu Qing, Zhang Hongmin, Liu Hui (2019): Applicability analysis of surface deformation monitoring in mining area with Sentinel-1A data [J]. Remote sensing of land and resources, 31 (02): 210-217

[6] Li Guangyu, Zhang Rui, Liu Guoxiang, Yu Bing, Zhang Bo, Dai Keren, Bao Jiawen, Wei Bowen (2018): Subsidence monitoring and analysis of Beijing Tianjin Hebei region by Sentinel-1 ATS-DInSAR [J]. Acta remote sensing, 22 (04): 633-646

[7] Xu Jun, Hu Jinshan, Kang Jianrong, Hua Yiying, Chen
Dan (2019): Land subsidence monitoring and analysis of mining villages based on SBAS-InSAR [J]. Metal mine, (10): 74-80

[8] Xiao Liang, He Yueguang, Xing Xuemin, Wen Debao, Tong Chenggong, Chen Lifu, Yu Xiaoying (2019): Sentinel-1 and SBAS-InSAR analysis of time series settlement of drilling water-soluble rock salt mine [J]. Acta remote sensing, 23 (03): 501-513

[9] Yin Hongjie, Zhu Jianjun, Li Zhiwei, Ding Xiaoli, Wang Changcheng (2011): Study on deformation monitoring in mining area based on SBAS [J]. Journal of surveying and mapping, 40 (01): 52-58

[10] Ng H M, Ge L, Yan Y, et al. (2010): Mapping accumulated mine subsidence using small stack of SAR differential inter-ferograms in the Southern coalfield of New South Wales, Australia[J]. Engg. Geology, 115(1-2):1-15.

[11] Liu Zhimin, Li Yongsheng, Zhang Jingfa, Luo Yi, Liu Bin (2014): Surface deformation monitoring in Changzhi mining area based on SBAS-InSAR [J]. Remote sensing of land and resources, 26 (03): 37-42

[12] Hua Yiying, Hu Jinshan, Kang Jianrong, Xu Jun (2020): Study on Surface Subsidence Law of multi working face mining in Daning mining area based on SBAS-DInSAR [J]. Metal mine, (03): 177-183

[13] Li Jinchao, Gao Fei, Lu Jiaguo, Fang Rui (2019): Deformation monitoring and prediction of residential areas based on SBAS-InSAR and GM-SVR [J]. Geodesy and geodynamics, 39 (08): 837-842

[14] Wang Yuanjian, Qi Lin, Jiang Yue, Yuan Xin, Li Pengyu, $\mathrm{Xu}$ Yongmei (2019): Subsidence monitoring and position inversion of old goaf in gold mine based on DInSAR technology [J]. Metal mine, (10): 68-73

[15] Liu Guoxiang, Zhang Bo, Zhang Rui, Cai Jialun, Fu Yin, Liu Qiao, Yu Bing, Li Zhilin (2019): Monitoring of Hailuogou Glacier dynamic change and secondary landslide disaster by combining Satellite SAR and ground-based SAR [J]. Journal of Wuhan University (Information Science Edition), 44 (07): 980-995

[16] Liu Tongqu (2019): Study on monitoring of coal mine surface subsidence based on SBAS-DInSAR technology [D]. Taiyuan University of Technology, 37-50

[17] Wright T J, Parsons B E, Lu Z. (2004): Toward mapping surface deformation in three dimensions using InSAR[J]. Geophysical Research Letters, 31(1):169-178.

[18] Samsonov S, Tiampo K. (2006): Analytical Optimization of a DInSAR and GPS Dataset for Derivation of ThreeDimensional Surface Motion[J]. IEEE Geoscience and Remote Sensing Letters, 3(1):107-111.

[19] Zhang Y, Meng X, Jordan C, et al. (2018): Investigating slow-moving landslides in the Zhouqu region of China using InSAR time series[J]. Landslides.

Blind peer reviews carried out 